Overall, peak GH level exceeded $10 \mu \mathrm{g} / \mathrm{l}$ in $31(50 \%)$ of 62 patients. Patients with no hypothalamic-pituitary abnormalities on MRI had significantly higher serum IGF-I levels than patients with ectopic neurohypophysis, but also had significantly lower serum IGF-I levels than healthy controls.

The authors conclude that some patients with childhood-onset GHD (with or without structural abnormalities) who have recovered normal GH levels when they reach adult height show subnormal serum IGF-I levels. Disease severity seems to be reduced in these patients, even though persistent pituitary failure might be present during early adulthood.

Original article Gelwane G et al. (2007) Subnormal serum insulin-like growth factor-I levels in young adults with childhood-onset nonacquired growth hormone (GH) deficiency who recover normal GH secretion may indicate less severe but persistent pituitary failure. J Clin Endocrinol Metab 92: 3788-3795

\section{Low testosterone levels linked to increased mortality}

A recent study has attributed low testosterone levels to earlier death in elderly men. Declining levels of serum testosterone have been considered as a factor leading to the deterioration of health in older men; however, there have been few scientific reports to back up this theory. Laughlin et al. carried out a prospective study of 794 men aged 50-91 years from 1984 to 2004 in a Southern California community. The group's median total testosterone level was $300 \mathrm{ng} / \mathrm{dl}$.

During the study, 538 deaths occurred. Men with total testosterone levels in the lowest quartile $(<241 \mathrm{ng} / \mathrm{dl})$ had a $40 \%$ higher risk of death over the following 20 years than men with normal testosterone levels. Other risk factors, such as age, pre-existing disease, obesity, and lifestyle choices were examined, but did not explain the association of low testosterone with mortality. Low testosterone levels appeared to increase the risk of death attributable to cardiovascular and respiratory disease (hazard ratios 1.38 [95\% Cl 1.02-1.85] and 2.29 [95\% Cl 1.25-4.20], respectively).

Testosterone levels above the median for this group did not show any clear survival advantage; therefore, the authors suggest randomized, placebo-controlled trials are needed to investigate the potential of physiologic testosterone-replacement therapy to extend duration and quality of life for elderly men with testosterone insufficiency.

Original article Laughlin GA et al. (2007) Low serum testosterone and mortality in older men. J Clin Endocrinol Metab [doi:10.1210/jc.2007-1792]

\section{Does the incidence of subclinical hypothyroidism increase with advancing age?}

Surks and Hollowell analyzed whether the increase of subclinical hypothyroidism with advancing age is caused by an increased incidence of thyroid disease in older people or by an age-related shift in the TSH-distribution curve towards higher values, the latter implying a higher reference range in older people. The upper reference limit for TSH concentrations is currently $4.5 \mathrm{mIU} / \mathrm{l}$.

Using National Health and Nutrition Examination Survey data, age-specific distribution of serum TSH and frequency-distribution curves for TSH within specific age groups were analyzed in individuals (age $\geq 12$ years; $n=16,533$ ) with no known thyroid abnormalities and not taking thyroid-related medications.

The percentage of individuals with TSH concentrations of $0.4-2.5 \mathrm{mlU} / \mathrm{l}$ progressively decreased with age, whereas the percentage of measurements $>4.5 \mathrm{mlU} / \mathrm{l}$ progressively increased. Frequency-distribution curves showed a shift in the peak relative frequency towards higher TSH concentrations with advancing age. A progressive increase in the mean, median and 97.5 centile for TSH concentration occurred with age, and the 97.5 centile was about $3.6 \mathrm{mlU} / \mathrm{l}$ in people aged $20-39$ years and $7.5 \mathrm{mlU} / \mathrm{l}$ in those over 70 years. Findings were qualitatively independent of the presence of antithyroid antibodies.

The prevalence of subclinical hypothyroidism might, therefore, currently be overestimated because a substantial proportion of individuals with $\mathrm{TSH}$ concentrations $>4.5 \mathrm{mIU} / \mathrm{I}$ have values below their age-specific 97.5 centile. The increasing 97.5 centiles for TSH that occur with aging seem to represent, at least in part, changes in the age-specific population distribution of TSH.

Original article Surks MI and Hollowell JG (2007) Agespecific distribution of serum thyrotropin and antithyroid antibodies in the U.S. population: implications for the prevalence of subclinical hypothyroidism. J Clin Endocrinol Metab 92: $4575-4582$ 